\title{
Perfectionism and depressive symptoms : The effects of psychological detachment from work
}

\section{Gluschkoff, Kia}

2017-10-01

Gluschkoff , K, Elovainio , M , Hintsanen , M , Mullola , S , Pulkki-Raback , L , Keltikangas-Jarvinen, L \& Hintsa , T 2017 , ' Perfectionism and depressive symptoms : The effects of psychological detachment from work ', Personality and Individual Differences, vol. 116 , pp. 186-190 . https://doi.org/10.1016/j.paid.2017.04.044

http://hdl.handle.net/10138/309439

https://doi.org/10.1016/j.paid.2017.04.044

cc_by_nc_nd

acceptedVersion

Downloaded from Helda, University of Helsinki institutional repository.

This is an electronic reprint of the original article.

This reprint may differ from the original in pagination and typographic detail.

Please cite the original version. 
Perfectionism and Depressive Symptoms: The Effects of Psychological Detachment from Work

Kia Gluschkoff, Marko Elovainio, Mirka Hintsanen, Sari Mullola, Laura Pulkki-Råback, Liisa Keltikangas-Järvinen, and Taina Hintsa

Author Note

Kia Gluschkoff, Marko Elovainio, Laura Pulkki-Råback, Liisa Keltikangas-Järvinen, and Taina Hintsa, Department of Psychology and Logopedics, Faculty of Medicine, University of Helsinki, Helsinki, Finland; Mirka Hintsanen, Unit of Psychology, Faculty of Education, University of Oulu, Oulu, Finland; Sari Mullola, Faculty of Educational Sciences, University of Helsinki, Helsinki, Finland.

Funding: This research was supported by the Kone Foundation (K.G., S.M., and T.H.) and the Academy of Finland (project 1297520, S.M. and project 258711, L.K.-J.).

Corresponding author: Kia Gluschkoff, Department of Psychology and Logopedics, Faculty of Medicine, P.O. Box 63, 00014 University of Helsinki, Finland. 


\begin{abstract}
We examined the association of perfectionism with depressive symptoms and tested whether psychological detachment from work would both mediate and moderate the association. The participants were 76 primary school teachers ( $87 \%$ female) who responded to measures of perfectionism (Multidimensional Inventory on Perfectionism in Sports adapted for teachers), psychological detachment from work (The Recovery Experience Questionnaire), and depressive symptoms (Beck Depression Inventory-II). Perfectionism comprised both adaptive and maladaptive dimensions. Adaptive perfectionism referred to striving for perfection, whereas maladaptive perfectionism involved negative reactions to imperfection and perceived pressure to be perfect. According to our results, negative reactions to imperfection were associated with higher depressive symptoms, and lower level of psychological detachment from work played a minor mediating role in the association. There was, however, no association between negative reactions to imperfection and higher depressive symptoms when detachment from work was high. Our findings suggest that striving for perfection and perceived pressure to be perfect might not contribute to depressive symptoms in teaching. Instead, teachers experiencing negative reactions to imperfection and low psychological detachment from work could be at risk for developing depressive symptoms. Finding ways to psychologically detach from work can benefit teachers characterized by negative reactions to imperfection.
\end{abstract}

Keywords: perfectionism, depressive symptoms, psychological detachment, teachers 


\section{Introduction}

Perfectionism is a personality trait with both adaptive and maladaptive aspects (Bieling, Israeli, \& Antony, 2004). Adaptive perfectionism is characterized by setting high personal standards and striving for flawlessness (Flett \& Hewitt, 2002) and it is associated with the Big Five trait of conscientiousness (Dunkley, Blankstein, Zuroff, Lecce, \& Hui, 2006). Maladaptive perfectionism, by contrast, encompasses negative reactions to mistakes, fear of failure, critical self-evaluations, and concerns regarding others' evaluations (Cox, Enns, \& Clara, 2002; Molnar, Sadava, Flett, \& Colautti, 2012). It is associated with neuroticism (Dunkley, Blankstein, et al., 2006) and is viewed as a stressor for individuals characterized by the trait (Chang, 2006; Chang, Watkins, \& Banks, 2004). Consequently, several studies have highlighted the role of maladaptive perfectionism as a risk factor for various forms of psychopathology, such as depression and depressive symptoms (Enns, Cox, \& Clara, 2002; Harris, Pepper, \& Maack, 2008).

It has been proposed that maladaptive perfectionism is linked to depression through various dysfunctional behaviors and cognitions (Dunkley, Sanislow, Grilo, \& McGlashan, 2006; Harris et al., 2008). In the context of working life, poor psychological detachment from work could represent such a dysfunctional cognition through which perfectionism affects mental health. Psychological detachment refers to disengaging mentally from work during leisure time (Sonnentag \& Kruel, 2006). It reduces strain and contributes to recovery process by implying that no further demands are placed on the same functional systems that were taxed during working hours (Sonnentag \& Fritz, 2007). Although evidence suggests that poor psychological detachment from work could be involved in the development of depressive symptoms (Sonnentag \& Fritz, 2007), it remains unclear whether adaptive and maladaptive 
perfectionism contribute to poor psychological detachment and whether psychological detachment, in turn, could act as a mediator of the effects of perfectionism on mental health.

In developing preventive strategies for depression, it is valuable to consider also moderating factors that can mitigate the adverse effects of perfectionism. Despite attempts to identify buffering factors that could protect maladaptive perfectionists from depression, there has been, thus far, little progress in detecting such factors (Ashby, Dickinson, Gnilka, \& Noble, 2011; Dunkley, Solomon-Krakus, \& Moroz, 2016; Zhou, Zhu, Zhang, \& Cai, 2013). However, prior research on perfectionism and depression has overlooked the potential buffering effects of psychological detachment from work. Importantly, it was recently proposed that besides having mediating effects, psychological detachment from work could also be a moderator of the association between stressors and mental health outcomes (Sonnentag \& Fritz, 2015). We apply this framework for the association between perfectionism and depressive symptoms by testing both the mediating and moderating effects of psychological detachment from work.

The current study examined the associations between adaptive and maladaptive aspects of perfectionism, psychological detachment from work, and depressive symptoms in a sample of primary school teachers. Compared with many other occupations, teachers report higher levels of occupational stress and show more signs of mental health problems (Johnson et al., 2005). Previously, maladaptive perfectionism has been identified as one of the factors increasing the risk of poor teacher mental health (Stoeber \& Rennert, 2008). Because the trait is associated with stress sensitivity (Luyten et al., 2011), it might have severe health consequences for individuals frequently exposed to stressful situations. Exploring ways of alleviating the adverse effects of perfectionism is, consequently, critical particularly in highstress professions such as teaching. 
We examined three dimensions of perfectionism tapping into its positive and negative aspects: striving for perfection (adaptive perfectionism), negative reactions to imperfection (self-oriented maladaptive perfectionism), and perceived pressure to be perfect (socially prescribed maladaptive perfectionism). Even though adaptive perfectionism is considered as a healthy striving for excellence and is, therefore, not usually associated with depression, including it in the study enabled us to investigate the associations between psychological detachment from work and both positive and negative facets of perfectionism. We, however, hypothesized that particularly the maladaptive dimensions of perfectionism would be associated with higher levels of depressive symptoms and that the associations could be mediated and moderated by psychological detachment from work.

\section{Method}

\subsection{Participants and Procedure}

Questionnaire data were collected between 2013-2014 from a randomized selection of primary schools in the Helsinki metropolitan area of Finland. Out of the initially selected 48 schools, 39 granted permission to conduct the study. Responses were received from 34 schools, representing $71 \%$ of the initial selection. The self-administered questionnaires were delivered to teachers' post boxes in the middle of the school term and included questions about demographics, working hours, perfectionism, psychological detachment from work, and depressive symptoms. A total of 76 primary schools teachers (66 female, 10 male), instructing grades one through six (7- to 12-year-old students) returned the questionnaires. The teachers were aged between 25 and 63 years $(M=43.95, S D=10.10)$. The age distribution $(33 \%<40$ years, 34\% 40-49 years, and 33\% $\geq 50$ years) and gender distribution (87\% female) of the teachers were comparable to national age and gender distributions among teachers in Finland 
(Finnish National Board of Education, 2013). The study was carried out in accordance with the ethical principles of the (masked for review), and the participants provided written informed consent.

\subsection{Measures}

We assessed perfectionism with the Multidimensional Inventory on Perfectionism in Sports adapted to teachers and the school context (Stoeber \& Rennert, 2008). The inventory includes three dimensions of perfectionism: striving for perfection (adaptive perfectionism, five items, e.g., "At school, it is important to me to be perfect in everything I attempt"), negative reactions to imperfection (self-oriented maladaptive perfectionism, five items, e.g., "At school, I feel extremely stressed if everything doesn't go perfectly"), and perceived pressure to be perfect (socially prescribed maladaptive perfectionism, 24 items, e.g., "My students expect my performance to be perfect"). The indicator of perceived pressure to be perfect

referred to overall socially prescribed maladaptive perfectionism that included pressure from colleagues, students, and the students' parents (eight items for each source of pressure, totaling to 24 items). The items were rated on a scale from 1 (never) to 6 (always). Mean scores were obtained for each dimension of perfectionism, with higher scores corresponding to greater perfectionism. Cronbach's alphas $(\alpha)$ for the scales ranged from .91 to .97 .

Psychological detachment from work was assessed with the Recovery Experience Questionnaire (REQ; Kinnunen, Feldt, Siltaloppi, \& Sonnentag, 2011; Sonnentag \& Fritz, 2007). The REQ measures psychological detachment from work with four items ( e.g., "During time after work, I don't think about work at all"). The items were rated on a scale ranging from 1 (totally disagree) to 5 (totally agree), and a mean score was calculated from the items. A higher score indicated a higher level of psychological detachment from work. The Cronbach's alpha for the scale was .82 . 
Depressive symptoms experienced during the past two weeks were measured with the Beck Depression Inventory-II (BDI-II; Beck, Steer, \& Brown, 1996). The 21-item scale measures self-rated depressive symptoms with four response alternatives ranging in intensity, coded from 0 to 3 (e.g., from "I don't cry any more than usual" to "I used to be able to cry, but now I can't cry even though I want to"). The answers were summed to yield a total score ranging from 0 to 63 , with higher scores corresponding to higher levels of depressive symptoms. The Cronbach's alpha for the scale was .90 .

\subsection{Statistical Analyses}

We first calculated bivariate correlations between the study variables. Next, we used linear regression analysis to explore the associations between perfectionism, psychological detachment from work, and depressive symptoms. The dimensions of perfectionism (i.e., striving for perfection, negative reactions to imperfection, and perceived pressure to be perfect) were examined both separately and after mutual adjustment. We additionally examined which dimension of perfectionism was the strongest predictor of psychological detachment from work and depressive symptoms by examining the dimensions using relative weight analysis (Tonidandel \& LeBreton, 2011). Compared with traditional indices produced by regression analysis, this method yields more accurate partitioning of variance explained among correlated predictors.

Bootstrap mediation analyses (PROCESS macro; Hayes, 2013) with 10000 resamples was conducted to examine the mediating effect of psychological detachment from work. The method is preferred in mediation analysis because it uses resampling with replacement and does not rely on the normality of the sampling distribution. Finally, we tested for interaction effects between each dimension of perfectionism and psychological detachment from work in three separate regression models predicting depressive symptoms. The predicting variables 
were mean centered before testing interactions, and all models were adjusted for age, gender, and total working hours. The analyses were performed using SPSS Statistics 22.0 and STATA 13 statistical software.

\section{Results}

Table 1 presents descriptive statistics and correlations for the study variables. There was a significant overlap between striving for perfection and negative reactions to imperfection $(\mathrm{r}=$ $.62)$, i.e., the participants tended to experience both adaptive and maladaptive aspects of perfectionism. Striving for perfection was positively correlated with total working hours $(\mathrm{r}=$ $.29)$ and depressive symptoms $(r=.27)$. Negative reactions to imperfection were negatively correlated with age $(r=-.33)$, psychological detachment $(r=-.31)$, and positively correlated total working hours $(r=.26)$, and depressive symptoms $(r=.47)$. Perceived pressure to be perfect was negatively correlated with age $(\mathrm{r}=-.31)$. Psychological detachment was negatively correlated with depressive symptoms $(r=-.40)$. The observed correlations also indicated gender differences, which were further investigated with the Welch's t-test for unequal sample sizes. Compared to men, women in our sample experienced more negative reactions to imperfection, $t(18.34)=2.62, p=.017$, less psychological detachment, $t(13.38)$ $=-2.19, p=.047$, and more depressive symptoms, $t(28.84)=4.08, p<.001$.

According to linear regression analyses adjusted for age, gender, and total working hours, only negative reactions to imperfection were associated with lower level of psychological detachment ( $\beta \mathrm{s}-.25$ and -.35 for mutually unadjusted and adjusted models, respectively, $p$-values $\leq .05$ ) (Table 2$)$. In addition, negative reactions to imperfection ( $\beta$ s .41 and .46 for mutually unadjusted and adjusted models, $p$-values $<.01)$ and lower level of psychological detachment $(\beta=-.34, p=.004)$ were associated with higher level of depressive 
symptoms. The results of relative weight analysis yielded similar results, highlighting the role of negative reactions to imperfection over the other dimensions of perfectionism in predicting the outcomes. When examined in a mutually adjusted model, the three dimensions of perfectionism and covariates explained $16 \%$ of the variance in psychological detachment and $25 \%$ of the variance in depressive symptoms. Among the dimensions of perfectionism, negative reactions to imperfection were the only significant predictor of both lower level of psychological detachment and higher depressive symptoms (43\% and $58 \%$ of the proportion of variance explained, respectively). In comparison, the relative importance of perfectionistic strivings and perceived pressure to be perfect in predicting the outcomes was relatively small (4-10\% of the proportion of variance explained).

The results of bootstrap mediation analysis conducted separately for each dimension of perfectionism suggested that lower level of psychological detachment from work mediated the association between negative reactions to imperfection and depressive symptoms by explaining $16 \%$ of the association ( $\beta=.06,95 \%$ CI .01 to .18 for the indirect effect) (Figure 1). Finally, we also observed a significant interaction between negative reactions to imperfection and psychological detachment from work $(\beta=-.28, \mathrm{p}=.011)$. While the association between negative reactions to imperfection and higher depressive symptoms was strongest with low psychological detachment, high level of psychological detachment from work completely attenuated the association (Figure 2).

\section{Discussion}

The present study examined the associations of adaptive and maladaptive aspects of perfectionism with depressive symptoms and tested both the mediating and moderating role of psychological detachment from work using a sample of primary school teachers. Our 
results showed that negative reactions to imperfection were associated with higher depressive symptoms and lower level of psychological detachment from work partially explained this association. However, there was no significant association between negative reactions to imperfection and depressive symptoms when psychological detachment from work was high.

The results are in agreement with the view on adaptive perfectionism as a healthy striving for excellence that does not necessarily lead to negative outcomes (Enns et al., 2002; Stoeber \& Childs, 2010). The concept of adaptive perfectionism is, however, strongly debated in the literature. According to a recent meta-analysis, depending on individual circumstances, all aspects of perfectionism can confer vulnerability to depression (Smith et al., 2016).

Consistent with previous research (Enns et al., 2002; Sherry et al., 2013; Sherry, Gautreau, Mushquash, Sherry, \& Allen, 2014), teachers experiencing negative reactions to imperfection reported higher levels of depressive symptoms. As for the observed mediating effects of psychological detachment from work, our findings support prior investigations that have shown various dysfunctional behaviors and cognitions to explain the association between maladaptive perfectionism and depression (Flett, Coulter, Hewitt, \& Nepon, 2011; Harris et al., 2008). In this study, the pathway from negative reactions to imperfection to depressive symptoms through psychological detachment from work was, however, relatively weak, suggesting that psychological detachment does not play a major mediating role in this process.

With regard to the moderating effect of psychological detachment, our findings suggest that high level of detachment from work during leisure time might protect teachers from the adverse effects negative reactions to imperfection. More specifically, there was no significant association between negative reactions to imperfection and depressive symptoms when psychological detachment from work was high. It is possible that by successfully detaching 
from work maladaptive perfectionists recover more efficiently from the stress of work hassles and escape from perfectionistic concerns that, in the long run, could otherwise contribute to higher depressive symptoms.

We did not observe an association between perceived pressure to be perfect and depressive symptoms, which contrasts not only with our initial hypothesis but also with findings from previous studies. This may be explained by the fact that, in teaching, socially prescribed perfectionism has been shown to have differential associations with both positive and negative outcomes depending on the source of perceived pressure (e.g., the students, their parents, or the teachers' colleagues) (Stoeber \& Rennert, 2008). The different sources of pressure were not separately investigated in the current study. Furthermore, recent evidence suggests that both the level and consequences of socially prescribed perfectionism are tied to the extent to which the individual's social environment involves exposure to criticism and demands to be perfect (Smith, Speth, et al., 2017; Smith, Saklofske, Yan, \& Sherry, 2017).

Taken together, our findings enhance the understanding of the associations between different facets of perfectionism, psychological detachment from work, and depressive symptoms. While the association of, for example, rumination with perfectionism and depressive symptoms is well-established (Harris et al., 2008), the contribution of this study lies in shedding light on the role of psychological detachment in this context. Whereas rumination involves focusing mentally on negative emotions and personal problems (NolenHoeksema, 2000), psychological detachment refers specifically to refraining from workrelated thoughts during leisure time (Sonnentag \& Fritz, 2015). Despite their partial overlap, rumination and psychological detachment represent two separate concepts as they are only moderately correlated (Donahue et al., 2012; Flaxman, Ménard, Bond, \& Kinman, 2012).

As a side note, younger teachers reported maladaptive forms of perfectionism most frequently. It is possible that experiencing maladaptive perfectionism is more common in 
early adulthood when teachers have only just started developing their professional competencies. An alternate explanation is that those teachers who experience maladaptive perfectionism could end up leaving the profession at a relatively early stage. Furthermore, particularly female teachers appeared to experience both lower levels of psychological detachment from work as well as higher levels of negative reactions to imperfection and depressive symptoms. Overall, this suggests that female novice teachers could be targeted in early interventions because they might have the highest risk of developing depressive symptoms. It is additionally worth noting that total working hours were not associated with psychological detachment from work, suggesting that other factors than high workload explain why teachers can have troubles detaching from work during leisure time.

The study contributes to the previous literature by investigating the effects of psychological detachment from work in the association between perfectionism and depressive symptoms. Methodological strengths of the study include the use of relative weight analysis and bootstrapping in examining the associations. We used BDI-II, an established and well-validated measure of depressive symptoms, which is another strength of the study. The study also has some limitations that should be acknowledged. Most importantly, because the study was cross-sectional, we cannot make any claims about causality. Although personality traits, such as perfectionism, are usually regarded as stable attributes, we cannot rule out the possibility that depressive symptoms contributed to negative reactions to imperfection. It has also been proposed that the association between negative reactions to imperfection and depressive symptoms could be reciprocal (McGrath et al., 2012). It should also be mentioned that the study had only a few participants from each of the selected schools, increasing the risk of nonresponse bias. The precise number of eligible teachers during the data collection period was not known, because limited information was available on the number of operating teachers in the participating schools and turnover in 
teacher personnel. Given the limitations, further longitudinal research is needed to test the reliability and wider applicability of our findings.

Despite the limitations, the current findings provide preliminary evidence on the effects of psychological detachment from work in the association between maladaptive perfectionism and depressive symptoms. Psychological detachment from work may partially mediate the association between maladaptive perfectionism and depressive symptoms in teaching. Our findings also demonstrate a moderating role for psychological detachment from work and suggest that high levels of detachment might protect teachers against the adverse effect of maladaptive perfectionism. Psychological detachment from work during leisure time can be a viable target for interventions aimed at preventing depressive disorders among teachers characterized by negative reactions to imperfection. 


\section{References}

Ashby, J. S., Dickinson, W. L., Gnilka, P. B., \& Noble, C. L. (2011). Hope as a Mediator and Moderator of Multidimensional Perfectionism and Depression in Middle School Students. Journal of Counseling \& Development, 89(2), 131-139. doi:10.1002/j.15566678.2011.tb00070.x

Beck, A., Steer, R., \& Brown, G. (1996). Manual for the Beck Depression Inventory-II. 1996. San Antonio, TX: Psychological Corporation.

Bieling, P. J., Israeli, A. L., \& Antony, M. M. (2004). Is perfectionism good, bad, or both? Examining models of the perfectionism construct. Personality and Individual Differences, 36(6), 1373-1385. doi:10.1016/S0191-8869(03)00235-6

Chang, E. C. (2006). Perfectionism and Dimensions of Psychological Well-Being in A College Student Sample: A Test of a Stress-Mediation Model. Journal of Social and Clinical Psychology, 25(9), 1001-1022. doi:10.1521/jscp.2006.25.9.1001

Chang, E. C., Watkins, A., \& Banks, K. H. (2004). How Adaptive and Maladaptive Perfectionism Relate to Positive and Negative Psychological Functioning: Testing a Stress-Mediation Model in Black and White Female College Students. Journal of Counseling Psychology, 51(1), 93-102. doi:10.1037/0022-0167.51.1.93

Cox, B. J., Enns, M. W., \& Clara, I. P. (2002). The multidimensional structure of perfectionism in clinically distressed and college student samples. Psychological Assessment, 14(3), 365-373. doi:10.1037/1040-3590.14.3.365

Donahue, E. G., Forest, J., Vallerand, R. J., Lemyre, P.-N., Crevier-Braud, L., \& Bergeron, É. (2012). Passion for Work and Emotional Exhaustion: The Mediating Role of Rumination and Recovery. Applied Psychology: Health and Well-Being, 4(3), 341-368. doi:10.1111/j.1758-0854.2012.01078.x 
Dunkley, D. M., Blankstein, K. R., Zuroff, D. C., Lecce, S., \& Hui, D. (2006). Self-Critical and Personal Standards factors of perfectionism located within the five-factor model of personality. Personality and Individual Differences, 40(3), 409-420. doi:10.1016/j.paid.2005.07.020

Dunkley, D. M., Sanislow, C. A., Grilo, C. M., \& McGlashan, T. H. (2006). Perfectionism and depressive symptoms 3 years later: negative social interactions, avoidant coping, and perceived social support as mediators. Comprehensive Psychiatry, 47(2), 106-115. doi:10.1016/j.comppsych.2005.06.003

Dunkley, D. M., Solomon-Krakus, S., \& Moroz, M. (2016). Personal standards and selfcritical perfectionism and distress: Stress, coping, and perceived social support as mediators and moderators. In Perfectionism, health, and well-being (pp. 157-176). Springer International Publishing.

Enns, M. W., Cox, B. J., \& Clara, I. (2002). Adaptive and maladaptive perfectionism: developmental origins and association with depression proneness. Personality and Individual Differences, 33(6), 921-935. doi:10.1016/S0191-8869(01)00202-1

Finnish National Board of Education. (2013). Teachers in Finland 2013. (T. Kumpulainen, Ed.). Tampere.

Flaxman, P. E., Ménard, J., Bond, F. W., \& Kinman, G. (2012). Academics' experiences of a respite from work: Effects of self-critical perfectionism and perseverative cognition on postrespite well-being. Journal of Applied Psychology, 97(4), 854-865. doi:10.1037/a0028055

Flett, G. L., Coulter, L.-M., Hewitt, P. L., \& Nepon, T. (2011). Perfectionism, Rumination, Worry, and Depressive Symptoms in Early Adolescents. Canadian Journal of School Psychology, 26(3), 159-176. doi:10.1177/0829573511422039

Flett, G. L., \& Hewitt, P. L. (2002). Perfectionism and maladjustment: An overview of 
theoretical, definitional, and treatment issues. In Perfectionism: Theory, research, and treatment. (pp. 5-31). Washington: American Psychological Association. doi:10.1037/10458-001

Harris, P. W., Pepper, C. M., \& Maack, D. J. (2008). The relationship between maladaptive perfectionism and depressive symptoms: The mediating role of rumination. Personality and Individual Differences, 44(1), 150-160. doi:10.1016/j.paid.2007.07.011

Hayes, A. F. (2013). Introduction to mediation, moderation, and conditional process analysis: A regression-based approach. New York, NY: The Guilford Press.

Johnson, S., Cooper, C., Cartwright, S., Donald, I., Taylor, P., \& Millet, C. (2005). The experience of work-related stress across occupations. Journal of Managerial Psychology, 20(2), 178-187. doi:10.1108/02683940510579803

Kinnunen, U., Feldt, T., Siltaloppi, M., \& Sonnentag, S. (2011). Job demands-resources model in the context of recovery: Testing recovery experiences as mediators. European Journal of Work and Organizational Psychology, 20, 805-832. doi:10.1080/1359432X.2010.524411

Luyten, P., Kempke, S., Van Wambeke, P., Claes, S., Blatt, S. J., \& Van Houdenhove, B. (2011). Self-Critical Perfectionism, Stress Generation, and Stress Sensitivity in Patients with Chronic Fatigue Syndrome: Relationship with Severity of Depression. Psychiatry: Interpersonal and Biological Processes, 74(1), 21-30. doi:10.1521/psyc.2011.74.1.21

McGrath, D. S., Sherry, S. B., Stewart, S. H., Mushquash, A. R., Allen, S. L., Nealis, L. J., \& Sherry, D. L. (2012). Reciprocal relations between self-critical perfectionism and depressive symptoms: Evidence from a short-term, four-wave longitudinal study. Canadian Journal of Behavioural Science / Revue Canadienne Des Sciences Du Comportement, 44(3), 169-181. doi:10.1037/a0027764

Molnar, D. S., Sadava, S. W., Flett, G. L., \& Colautti, J. (2012). Perfectionism and health: A 
mediational analysis of the roles of stress, social support and health-related behaviours. Psychology \& Health, 27(7), 846-864. doi:10.1080/08870446.2011.630466

Nolen-Hoeksema, S. (2000). The role of rumination in depressive disorders and mixed anxiety/depressive symptoms. Journal of Abnormal Psychology, 109(3), 504-511. doi:10.1037/0021-843X.109.3.504

Sherry, S. B., Gautreau, C. M., Mushquash, A. R., Sherry, D. L., \& Allen, S. L. (2014). Selfcritical perfectionism confers vulnerability to depression after controlling for neuroticism: A longitudinal study of middle-aged, community-dwelling women. Personality and Individual Differences, 69, 1-4. doi:10.1016/j.paid.2014.04.035

Sherry, S. B., Nealis, L. J., Macneil, M. A., Stewart, S. H., Sherry, D. L., \& Smith, M. M. (2013). Informant reports add incrementally to the understanding of the perfectionismdepression connection: Evidence from a prospective longitudinal study. Personality and Individual Differences, 54(8), 957-960. doi:10.1016/j.paid.2013.01.002

Smith, M., Saklofske, D. H., Yan, G., \& Sherry, S. B. (2017). Does Perfectionism Predict Depression, Anxiety, Stress, and Life Satisfaction After Controlling for Neuroticism? A Study of Canadian and Chinese Undergraduates. Journal of Individual Differences, In Press. doi:10.1027/1614-0001/a000223

Smith, M., Sherry, S. B., Rnic, K., Saklofske, D. H., Enns, M., \& Gralnick, T. (2016). Are Perfectionism Dimensions Vulnerability Factors for Depressive Symptoms After Controlling for Neuroticism? A Meta-analysis of 10 Longitudinal Studies. European Journal of Personality, 30(2), 201-212. doi:10.1002/per.2053

Smith, M., Speth, T. A., Sherry, S. B., Saklofske, D. H., Stewart, S. H., \& Glowacka, M. (2017). Is socially prescribed perfectionism veridical? A new take on the stressfulness of perfectionism. Personality and Individual Differences, 110, 115-118. doi:10.1016/j.paid.2017.01.031 
Sonnentag, S., \& Fritz, C. (2007). The Recovery Experience Questionnaire: development and validation of a measure for assessing recuperation and unwinding from work. Journal of Occupational Health Psychology, 12, 204-221. doi:10.1037/1076-8998.12.3.204

Sonnentag, S., \& Fritz, C. (2015). Recovery from job stress: The stressor-detachment model as an integrative framework. Journal of Organizational Behavior, 36(S1), S72-S103. doi:10.1002/job.1924

Sonnentag, S., \& Kruel, U. (2006). Psychological detachment from work during off-job time: The role of job stressors, job involvement, and recovery-related self-efficacy. European Journal of Work and Organizational Psychology, 15(2), 197-217. doi:10.1080/13594320500513939

Stoeber, J., \& Childs, J. H. (2010). The Assessment of Self-Oriented and Socially Prescribed Perfectionism: Subscales Make a Difference. Journal of Personality Assessment, 92(6), 577-585. doi:10.1080/00223891.2010.513306

Stoeber, J., \& Rennert, D. (2008). Perfectionism in school teachers: Relations with stress appraisals, coping styles, and burnout. Anxiety, Stress \& Coping, 21(1), 37-53. doi:10.1080/10615800701742461

Tonidandel, S., \& LeBreton, J. M. (2011). Relative Importance Analysis: A Useful Supplement to Regression Analysis. Journal of Business and Psychology, 26(1), 1-9. doi:10.1007/s10869-010-9204-3

Zhou, X., Zhu, H., Zhang, B., \& Cai, T. (2013). Perceived Social Support as Moderator of Perfectionism, Depression, and Anxiety in College Students. Social Behavior and Personality: An International Journal, 41(7), 1141-1152.

doi:10.2224/sbp.2013.41.7.1141 
Table 1

Descriptive statistics and correlations between the study variables

\begin{tabular}{|c|c|c|c|c|c|c|c|c|c|}
\hline Variable & $\mathrm{M}$ & $\mathrm{SD}$ & 1 & 2 & 3 & 4 & 5 & 6 & 7 \\
\hline 1. Age & 43.95 & 10.10 & - & & & & & & \\
\hline 2. Gender ${ }^{\mathrm{a}}$ & 0.13 & 0.34 & $.38 * * *$ & - & & & & & \\
\hline 3. Total working hours & 36.49 & 5.13 & -.10 & -.03 & - & & & & \\
\hline 4. Striving for perfection & 3.36 & 1.22 & -.17 & -.14 & $.29 *$ & - & & & \\
\hline 5. Negative reactions to imperfection & 2.12 & 0.94 & $-.33 * *$ & $-.23 *$ & $.26^{*}$ & $.62 * * *$ & - & & \\
\hline 6. Perceived pressure to be perfect & 2.36 & 0.97 & $-.31 * *$ & -.15 & .17 & $.37 * *$ & $.43 * *$ & - & \\
\hline 7. Psychological detachment from work & 3.29 & 0.87 & .15 & $.23 *$ & -.19 & -.18 & $-.31 * *$ & -.04 & - \\
\hline 8. Depressive symptoms & 5.42 & 5.90 & -.18 & $-.31 * *$ & .17 & $.27 *$ & $.47 * * *$ & .23 & $-.40 * * *$ \\
\hline
\end{tabular}

Note. $N=70-76 .{ }^{\mathrm{a}} 0=$ female; $1=$ male. All correlations are Pearson correlations except for binary variables (gender), for which Spearman correlations were used.

$* p<.05 ; * * p .01 ; * * * p<.001$ 


\section{Table 2}

The associations between perfectionism, psychological detachment from work, and depressive symptoms

\begin{tabular}{|c|c|c|c|c|c|c|}
\hline \multirow[b]{2}{*}{ Predictor } & \multicolumn{3}{|c|}{$\begin{array}{l}\text { Psychological detachment } \\
\text { from work }\end{array}$} & \multicolumn{3}{|c|}{$\begin{array}{c}\text { Depressive } \\
\text { symptoms }\end{array}$} \\
\hline & Model I & $\begin{array}{l}\text { Model } \\
\text { II }\end{array}$ & $\begin{array}{l}\text { Relative } \\
\text { weight }\end{array}$ & Model I & $\begin{array}{l}\text { Model } \\
\text { II }\end{array}$ & $\begin{array}{l}\text { Relative } \\
\text { weight }\end{array}$ \\
\hline \multicolumn{7}{|l|}{ Adaptive perfectionism } \\
\hline Striving for perfection & -.11 & .04 & $8 \%$ & .24 & -.07 & $10 \%$ \\
\hline \multicolumn{7}{|l|}{ Maladaptive perfectionism } \\
\hline Negative reactions to imperfection & $-.25 *$ & $-.32 *$ & $43 \%$ & $.41 * * *$ & $.46^{* *}$ & $58 \%$ \\
\hline Perceived pressure to be perfect & .01 & .14 & $4 \%$ & .16 & .02 & $7 \%$ \\
\hline Covariates (age, gender, and total & & & $45 \%$ & & & $25 \%$ \\
\hline \multicolumn{7}{|l|}{ working hours) } \\
\hline Total & & & $100 \%$ & & & $100 \%$ \\
\hline
\end{tabular}

Note. $N=69-70$. For Models I and II, the estimates are standardized $\beta \mathrm{s}$. Model I: each predictor is analyzed separately. Model II: all predictors are included in the model. Relative weights are presented as the proportion of total variance explained when the predictors are in the same model. All estimates are adjusted for age, gender, and total working hours. ${ }^{*} p \leq .05 ; * * p<.01 ; * * * p<.001$. 


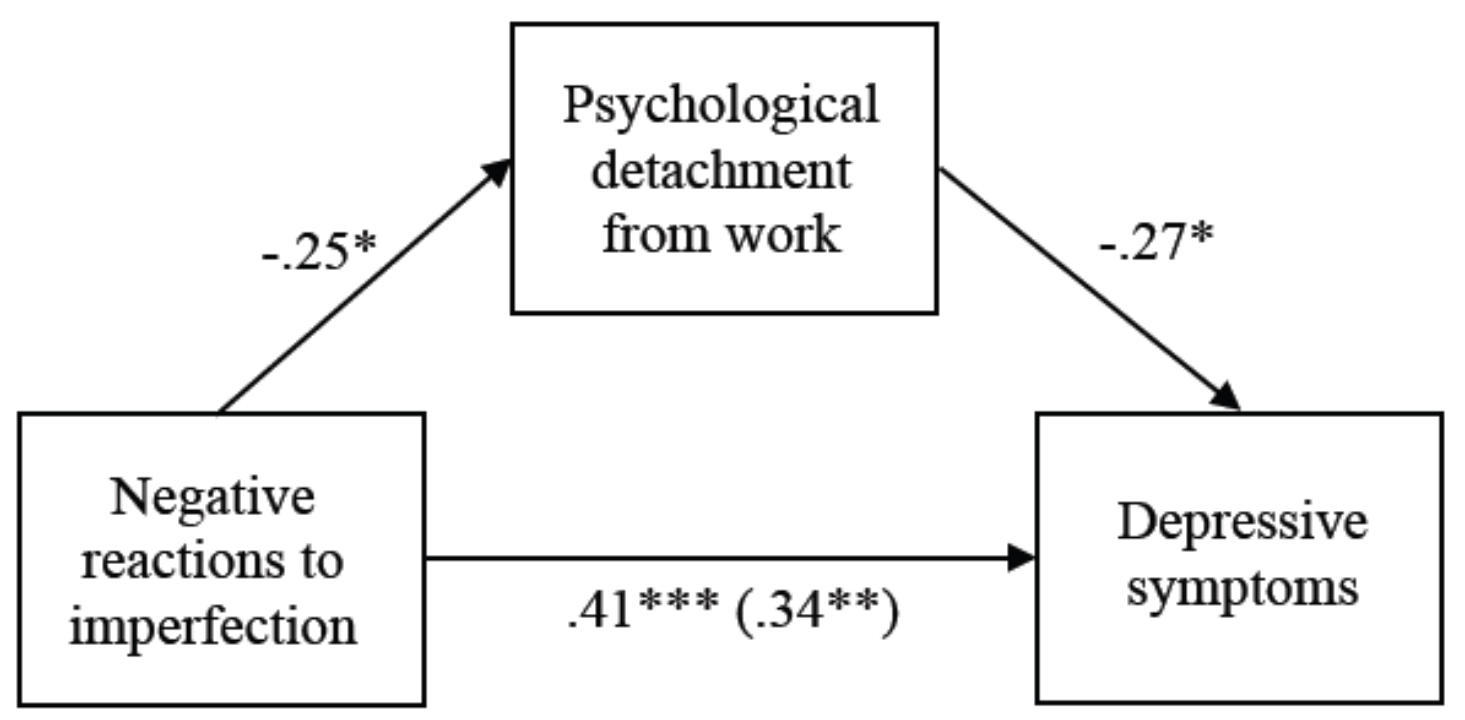

Figure 1. The indirect association between negative reactions to imperfection and depressive symptoms through psychological detachment from work. Adjusted for age, gender, and total working hours. ${ }^{*} p \leq .05 ; * * p<.01 ; * * * p<.001$. 


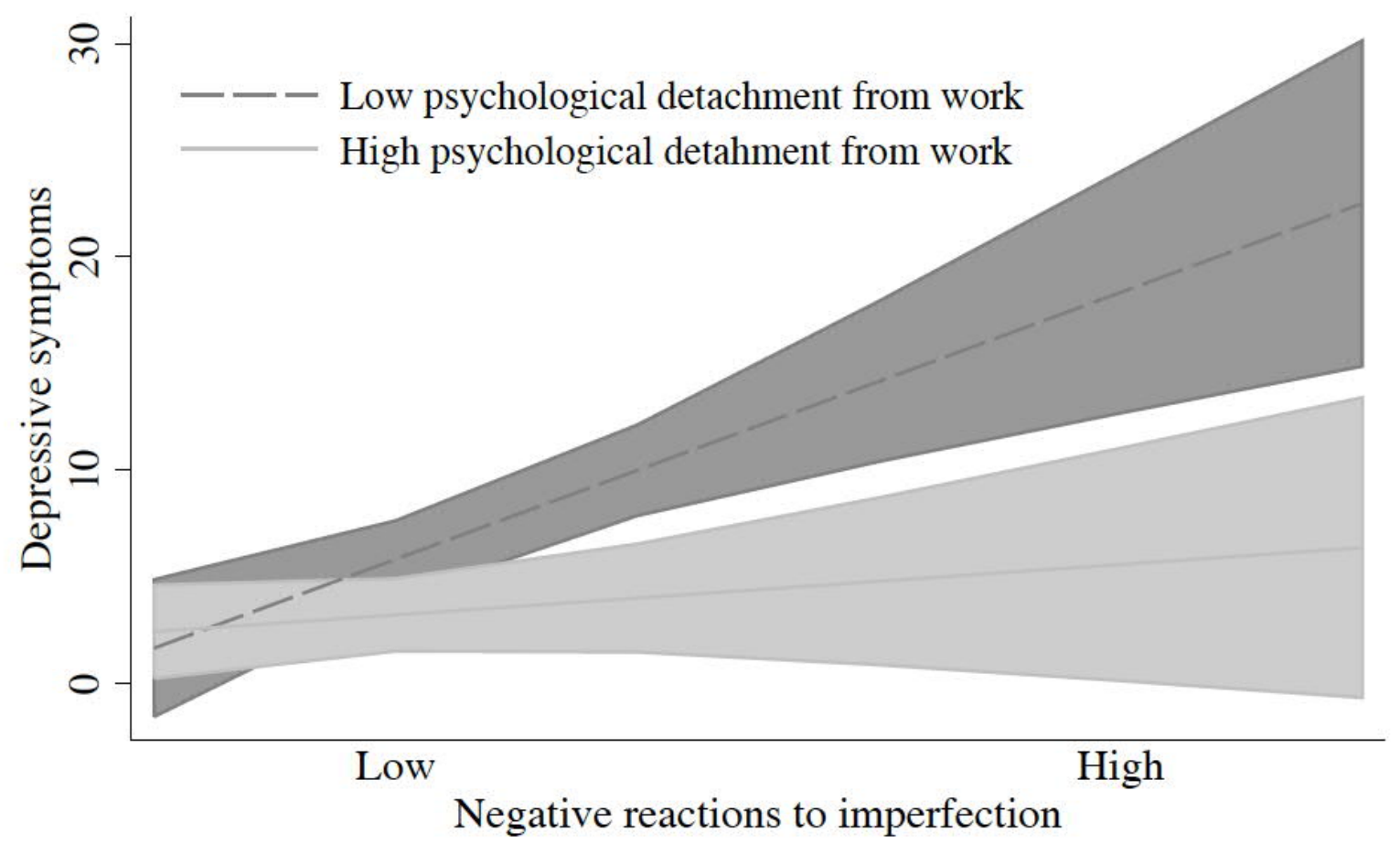

Figure 2. The association between negative reactions to imperfection and depressive symptoms by high and low levels of psychological detachment from work $( \pm 1$ SD from the mean). Adjusted for age, gender, and total working hours. 